in these tables. The yellow color is probably somewhat easier to "match" than the pink, and its use is advised when the higher concentrations are concerned. It is also of considerable advantage in that it affords a ready check upon the determination by the pink color, a matter of importance when such small amounts of unknown solutions are available as to preclude duplicate determinations. The yellow color is not so deep or strong, however, as the pink, and for this reason the latter is much more advantageous than the former, when high dilutions are concerned.

From what has been presented in this paper, it is evident that we have here a very sensitive method, susceptible of a high degree of accuracy, for determining quantitatively minute quantities of potassium. No unusual apparatus or skill is required for its manipulation. But it will only yield satisfactory results when care is exercised, and especially in the handling and washing of the small precipitate of potassium platinic chloride. The limit of dilution to which the method is applicable is probably much higher than the figures given here would indicate, but we have not attempted to determine this limit, and are not prepared to make a more definite statement concerning it.

BUREAU OF SOILS,

U. S. DEPARTMENT OF AGRICULTURE,

WAShINGTON, D. C.

\title{
THE ESTIMATION OF TITANIUM.
}

By J. Watson Bain.

Received August 17, 1903.

OF THE many elements which present themselves for determination to the metallurgical chemist of to-day, there are a select few which have won for themselves a reputation based upon the tediousness or the difficulty of the preliminary separation from other constituents which may be present. In this class of unenviable reputation we may place the element titanium for, although its determination presents no difficulties to the experienced chemist with time at his disposal, his less fortunate brother, at the same task in the rush of a works laboratory, is apt to find that either speed or accuracy must be sacrificed in answer to the demands made on him.

For three-quarters of a century the estimation of this element 
in all pure solutions involved six or eight hours' boiling, an operation which had often to be repeated, or else a tedious treatment with ammonium sulphicle, until Gooch ${ }^{1}$ discovered that titanium could be precipitated quantitatively in a convenient form by a few minutes' boiling, and. Blair" added to this a modification which permitted a much more rapid separation from iron than heretofore. Thus the determination became comparatively casy, but nevertheless under the pressure of heavy work and insufficient time, the demand for a shorter method has become notice. able and in response several modified processes have appeated in the chemical literature of the clar. To inquire into the accuracy of these was the first object of the following investigation. At the same time it has not been considered necessary to confine the attention to speed, and hence some experiments have been incorporated simply because they have a bearing upon the estimation of titanium in general. In the foregoing statements, there has been a reservation regarding Weller's" excellent colorimetric method; it is rapid and accurate, but unfortmately is only adlapted for the estimation of small quantities of titanium.

To the chemist engaged in the analysis of minerals and rocls the separation of titanium from some of the rarer elements such as zirconium or vanadium is a matter clemanding attention, but to the metallurgical chemist who meets these more uncommon clements either rarely or in minute quantities, the elimination of iron, aluminum and phosphorus is usually the only problem to be considered. For this reason, the behavior of these last three elements, with the one under consideration, has been the object of this study. At the same time it will readily be seen that all our present knowledge can be directly employed in the final stages of any of the methods investigated.

Without referring in cletail to the modifications of the older processes, descriptions of which are to be found in modern chemical or metallurgical journals, it is proposed to discuss the merits of three methods which are apparently new in principle. In the following pages, these have been designated for convenience by the author's name; if any injustice has been done, the writer begs to offer his apologies.

1 Gooch: Bull. 27, U. S. Geol. Survey, p. 16; Proc. An. Acad. Arts Sit. a. s., 12, 435 ; Cheme. New', 72, 55, 68 .

2 Blait's "Analysis of Iron and steel, "4th edition, p. I.9.

3 Ber, a. chem. Ges., 15, 2593. 
For the purpose of the investigation a solution of pure titanium dioxide was necessary, and this was prepared from rutile by Wöhler's ${ }^{1}$ method. The mineral at hand, however, was very impure and only a small yield of potassium fluotitanite was obtained. The process was therefore modified by preparing, according to the directions of Streit and Franz, ${ }^{2}$ a quantity of fairly pure titanium dioxide, which was then converted into the fluotitanate and finally by the action of strong sulphuric acid into titanium sulphate. Incidentally it may be mentioned that this modification is much more convenient for the preparation of considerable quantities of pure potassium fluotitanate, but Merz's ${ }^{3}$ process, a description of which was found after the preparation had been made, appears to be the best. After the removal of the excess of sulphuric acid, the pasty mass of potassium and titanium sulphates was treated with water, solution being accelerated by warming to $70^{\circ} \mathrm{C}$. and agitating with a blast of air. After suitable dilution, ammonia was added to weighed quantities of this standard solution till alkaline, followed by acetic acid in decided excess ${ }^{4}$ and the titanium dioxide, precipitated by boiling for two or three minutes, was filtered off, thoroughly washed, and ignited to constant weight.

$\begin{array}{ccc}\begin{array}{c}\text { Weight of } \\ \text { solution. } \\ \text { Grams. }\end{array} & \begin{array}{c}\mathrm{TiO}_{2} \\ \text { found. }\end{array} & \begin{array}{c}\mathrm{TiO}_{2} \mathrm{in}_{\text {25 grams }} \\ \text { standard solution. } \\ \text { Gram. }\end{array} \\ 27.8603 & \text { Gram. } & 0.2343 \\ 27.8518 & 0.26 \mathrm{II} & 0.2355 \\ 27.8384 & 0.2624 & 0.2356 \\ 27.8540 & 0.2624 & 0.235 \mathrm{I} \\ & 0.2620 & \underline{0.235 \mathrm{I}}\end{array}$

Every precaution was taken to make these results as accurate as possible, and it is believed that the mean approximates very closely to the true value.

\section{BASKFRVILLE'S METHOD.}

The detailed description ${ }^{5}$ may be briefly summarized as follows : The material is fused with potassium bisulphate and the mass dissolved in water, ammonia is added till alkaline, and the hy-

\footnotetext{
1 Wöhler: $A m$. Chem. Pharm., 74, 212.

2 Streit and Franz: J. prakt. Chem., 108, 65; Ztschr. Chem. [2], 6, 256.

3 Merz:J.prakt. Chem., 99, I57.

1 Gooch : Loc, cit.

5 Baskerville: $J$. Soc. Chem. Ind., 19,419; also this Journal, 16, 427.
} 
droxides are filtered off, washed and redissolved in hydrochloric acic. Ammonia is then added till the solution reaches the socalled neutral point and the volume is brought to about Ioo cc., sulphur dioxide is passed in to saturation, and three minutes' boiling precipitates the titanium dioxide. If the latter be not perfectly white, the process is repeated. One point deserves attention. After dissolving the hydroxicle precipitated by ammonia in Is cc. of dilute hydrochloric acid, to quote the original: "Very dilute ammonium hydroxide is now added slowly to neutralize the acid. When a slight permanent precipitate is obtained, I per cent. hydrochloric acid is added drop by drop, boiling after each arldition until the solution just becomes clear: the total amount of liquicl should not be more than 100 cc." The writer has endeavored to follow out these directions in a number of cases, but has always failed to secure the desired effect. The I per cent. hydrochloric acid will not dissolve the precipitate even after a large quantity has been added, and this result could be predicted from a knowledge of the behavior of salts of titanitum in solution. For example, a solution containing titanium and ferric chlorides, after being nearly neutralized, but while still free from the faintest trace of a precipitate, becomes turbid on boiling, and the metatitanic acid thus precipitated is apparently quite unattacked by I per cent. lyydrochloric acid even in considerable amount. The following modification was, therefore, adopted in the experiments to be described: Dilute ammonia was added to the solution of the chlorides until a faint permanent precipitate was formed which was just redissolved with a drop or two of dilute hydrochloric acid, or in other words, the solution was treated exactly as though a basic acetate separation were to be made. In all other details the method was carefully followed, notwithstanding the fact that slight alterations suggested themselves from time to lime.

The Separation of Titanium from Iron.-Iron is almost invariably present in the materials in which titanium is to be estimated, and consequently this separation was the first to be studied. To a weighed quantity of the standard solution, 0.5 gram iron as $\mathrm{Fe}_{2}\left(\mathrm{SO}_{4}\right)_{3}$ was added, then ammonia to alkalinity, followed by acetic acid in slight excess. The latter reagent was employed because it was thought that traces of titanium, which might have escaped precipitation with ammonia alone, would then be thrown 
down, although no direct experiments were made to settle the point. It will be remembered, however, that Gooch found advantageons the presence of a distinct excess of acetic acid when estimating tit:ınium in a pure solution. The hydroxides, after washing till the sulphates were almost entirely removed, were dissolved in dilute hydrochloric acid, and the solution neutralized with ammonia till a faint permanent precipitate was formed, which was redissolved in a drop or two of dilute acid. Sulphur dioxide was then passed in tc saturation; in the course of a few minutes a white precipitate usually began to form. After boiling for five minutes the hydrated titanium dioxide separated out in flocks, and the supernatant liquid showed the characteristic, faint greenish tinge of solutions containing ferrous chloride. The precipitate was filtered off, washed with hot water, and ignited to constant weight.

\begin{tabular}{|c|c|c|c|c|}
\hline (3) $\ldots \ldots$ & $\begin{array}{c}\text { Weight of } \\
\text { solution. } \\
\text { Grams. } \\
6.639\end{array}$ & $\begin{array}{c}\mathrm{TiO}_{2} \\
\text { found. (I) } \\
\text { Gram. } \\
0.0662\end{array}$ & $\begin{array}{c}\text { TiO by } \\
\text { standard. } \\
\text { Gram. } \\
0.0624\end{array}$ & $\begin{array}{c}\text { Error. } \\
0.0038+\end{array}$ \\
\hline (4) $\ldots \ldots$ & $7 \cdot 720$ & 00707 & 0.0684 & $0.0023+$ \\
\hline$(5) \ldots \ldots$ & I I. I 69 & 0.1136 & 0.1050 & $0.0086+$ \\
\hline (6) $\ldots \ldots$ & 11.167 & 0.1138 & 0.1050 & $0.0088+$ \\
\hline (7) $\ldots \ldots$ & 11.085 & not & 0.1045 & ....... \\
\hline (8) $\ldots \ldots$ & 11.087 & weighed. & 0.1045 & $\ldots \ldots$ \\
\hline (g) $\ldots \ldots$ & II. 337 & 0.1062 & 0.1049 & $0.0013+$ \\
\hline (10) $\ldots \ldots$ & . II.140 & $0.5 \operatorname{IoS}$ & 0.1049 & $0.0059 t$ \\
\hline
\end{tabular}

As will readily be understood, the amount of iron thrown down with the titanium dioxide depends on the manner in which the solution is neutralized. Where this was carried out with the greatest care, the solution being only gently warmed till completely reduced, as was the case in (4) and (9), the results approximated to the truth with exactness sufficient, at least, for technical work; this accuracy is, however, due to a balancing of errors, as will be shown later on. Numbers ( 7 ) and (8) were treated with ammonia till a faint precipitate remained persistently; on heating, the turbidity appeared to become less, and before $100^{\circ} \mathrm{C}$. had been reached, the burner was removed and sulphur dioxide passed in. The first few bubbles produced a reddish white precipitate; after saturation and boiling, this turned brownish red in color and evidently contained a considerable quantity of iron. This became more apparent on ignition and no weighings were made at this stage. The purity of the titanium dioxide may be 
judged roughly from its color after precipitation; if snow-white, iron is almost entirely absent, but when contaminated with that element, a reddish or pinkish tinge is noticeable, the more pronounced the greater the impurity. The same effects may also be noted in the ignited precipitate. The precipitates were clissolved, if very impure, by treatment with potassium bisulphate, or otherwise by fusion with sodium carbonate and solution in concentrated sulphuric acid; in the former case, care was taken to remove from the solution subsequently obtained, the platinum from the crucible. The entire process as described above was then repeated, yielding the fcllowing results:

\begin{tabular}{|c|c|c|c|c|}
\hline & $\begin{array}{l}\text { Weight of } \\
\text { solution. } \\
\text { Grams. }\end{array}$ & $\begin{array}{l}\text { Tion } \\
\text { found. (II) } \\
\text { Gram. }\end{array}$ & $\begin{array}{l}\text { Tioby } \\
\text { standard. } \\
\text { Gram. }\end{array}$ & litror. \\
\hline (3) $\ldots \ldots$ & 6.639 & 0.0580 & 0.0624 & 0.0044 \\
\hline (4) $\ldots \ldots$ & 7.270 & 0.0655 & 0.0684 & 000,3 \\
\hline (5) $\ldots \ldots \ldots$ & II. I69 & 0.1032 & 0.1050 & $0.0018-$ \\
\hline (6) $\ldots \ldots \ldots$ & II. 167 & $0.103 i$ & 0.1050 & 0.0019 \\
\hline ( 7$) \ldots \ldots$ & 11.085 & 0.1056 & 0.1045 & 0.0011 \\
\hline (8) $\ldots \ldots$ & I 1.087 & 0.1027 & 0.1045 & $0.0018-$ \\
\hline (g) $\ldots \ldots \ldots$ & 11.137 & 0.1012 & 0.10 .49 & 0.0137 \\
\hline (I0) $\ldots$. & II. I 40 & 0.1025 & 0.1049 & 0.0024 \\
\hline
\end{tabular}

Some of these precipitates still retained iron and the results should be corrected before criticism is made; determinations were not carried out in (3) and (4), and in (6), which was accidentally lost after estimating the platinum, iron was also present, and the error is greater than -0.0019 gram.

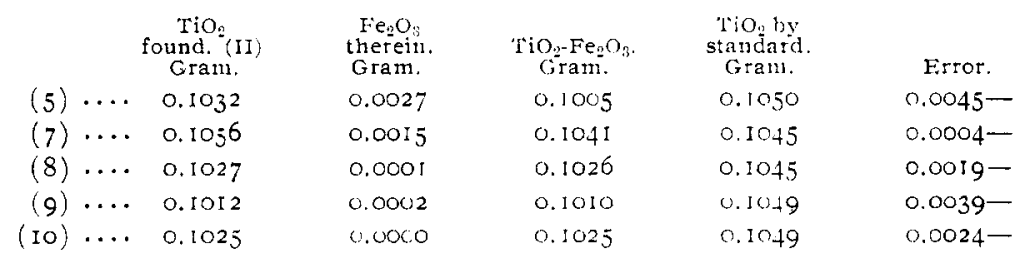

From these results, some interesting deductions can be drawn. In the first place, it will be remembered that in ( 7 ) and (8) so much iron was thrown down in the first precipitation that the weighing was omitted, and it will be seen that in these two instances the final errors are the lowest of all. One might therefore purposely produce a similar condition with a view of attaining greater accuracy. Again it will be observed that, presumably, after experience in the operation had been gained, the second 
precipitation yielded titanium dioxide practically free from iron, as shown in (8), (9), and (10), but apparently always at the expense of a loss in the titanium. Omitting $(7)$ as exceptional, the average loss in the element under estimation is 3 per cent. In most of the filtrates, colorimetric estimations were made of the titanium which remained in solution, but no light was thrown upon the question as to the conditions under which the greatest loss took place. The amounts found varied from traces to 1.5 milligrams.

From the standpoint of technical work, the uncorrected results of the second precipitation are worth noting. The errors here can be overlooked in view of the fact that titanium is not bought and sold at so much per unit, and if a small amount of iron remain in the final precipitate it serves but to balance the loss in the element estimated. An interesting case may be cited at this point as an instance of the curiously exact results which may sometimes be obtained in cases in which all precautions are not taken. The impure titanium dioxide obtained in the first precipitation in (5) and (6) was fused with potassium bisulphate, and inadvertently the second precipitation was made without removing the platinum by hydrogen sulphide as usual. After weighing, the precipitates were fused again with potassium bisulphate in porcelain and the platinum and iron estimated; in (6), an accident prevented the completion of this operation after the platinum, which amounted to 0.0019 gram, had been determined.

$$
\begin{gathered}
\text { TiO o by } \\
\text { standard. } \\
\text { Gram. }
\end{gathered}
$$

0.1050

0.1050

$$
\begin{aligned}
& \mathrm{TiO}_{2} \\
& \text { found. } \\
& \text { Gram. }
\end{aligned}
$$

0.1059

0.1050
$\mathrm{TiO}_{2}$ found

less impurities. Gram.

O. 1005

o. 103 I (less Pt only.)

It may be remarked at this point that Baskerville makes no provision for the removal of the platinum which is always present after a fusion with potassium bisulphate and that this precaution may only be neglected in the hope that a balancing of errors will ensue.

The Separation of Titanium and Aluminum.-To weighed quantities of the standard solution were added 1.75 -gram portions of alum, equivalent to 0.1877 gram alumina. The hydroxides were precipitated with ammonia, washed, redissolved in hyd:ochloric acid, the solution neutralized with ammonia and after dilution to $100 \mathrm{cc}$, boiled for three minutes. 


\begin{tabular}{|c|c|c|c|c|}
\hline & $\begin{array}{l}\text { Weight of } \\
\text { solution. } \\
\text { Grams. }\end{array}$ & $\begin{array}{l}\mathrm{TiO}_{3} \\
\text { foutd. } \\
\text { Gram. }\end{array}$ & $\begin{array}{l}\mathrm{TiO}_{2} \text { by } \\
\text { standard. } \\
\text { Gram. }\end{array}$ & Error. \\
\hline (II) & . 6.ros & 0.0575 & 0.0574 & $0.000 \mathrm{I}+$ \\
\hline (12) & 6.215 & 0.0592 & 0.0584 & $0.0008-$ \\
\hline (I3) & I I. I 85 & 0.1076 & 0.1052 & 0.0024 \\
\hline (I4) & {$[1,177$} & 0.1044 & 0.1052 & $0.0008-$ \\
\hline
\end{tabular}

To ascertain what quantity of alumina still remained in these precipitates, recourse was had to Gooch's method which assured the separation of the small amount retained without the risk of losing any of the titanium. The precipitates were accordingly fused with pure sodium carbonate, leached with water, re-fused with sodium carbonate and treated with concentrated sulphuric acid until complete solution took place. The remaining steps of the process were carried out as usual, the titanium being precipitated from a solution strongly acidified with acetic acirl. After this treatment the following results were obtained:

\begin{tabular}{|c|c|c|c|c|}
\hline & $\begin{array}{l}\text { Weight of } \\
\text { solution. } \\
\text { Grams. }\end{array}$ & $\begin{array}{l}\text { Tio. } \\
\text { found. (II) } \\
\text { Gram. }\end{array}$ & $\begin{array}{c}\text { TiO, by } \text { by } \\
\text { standard. } \\
\text { Gram. }\end{array}$ & Error. \\
\hline (II) & . 6.105 & $\ldots$. & 0.0574 & $\ldots$ \\
\hline (12) & . 6.215 & 0.0582 & $0.05^{84}$ & $0.0002-$ \\
\hline$\left(I_{3}\right)$ & . II.185 & 0.1044 & o. 1052 & $0.0008-$ \\
\hline (I4) & . I. 177 & 0.1036 & 0.1052 & $0.0016-$ \\
\hline
\end{tabular}

It will thus be seen that with the smaller amounts of titanium in (II) and (I2), the separation from a fairly large quantity of alumina is remarkably sharp for one precipitation, much more so than in any of the cases given by Gooch as examples of the efficiency of his method. Even the larger quantities of titanium dioxide retain only trifling quantities of alumina, and it is easy to arrange for their removal. Having regard to the observation which has been made in the course of this study that minute but determinable quantities of titanium are almost invariably to be found in the filtrates from Baskerville's method, but very much smaller quantities or only traces in the filtrates from Gooch's method, and desiring to avoid loss as far as possible, the following would appear to be the best method of purification. The impure titanium dioxide is fused with pure sodium carbonate, leached with water, re-fused with sodium carbonate, and the melt dissolved in concentrated sulphuric acid by gentle warming; the titanium dioxide in this solution is then precipitated according to Gooch's directions.

The Separation of Titanim and Phosphorus.-The fact that 
titanium phosphate is almost insoluble in dilute hydrochloric acid would lead to the prediction that a separation of these elements uncler the conditions laid down by Baskerville could not be expected, and consequently no experiments were made in this direction. A little later, however, some evidence bearing on this point will be presented.

The Separation of Titanium from Iron, Aluminum and Phosphorus.-Since these elements present themselves in varying quantities in nearly every instance in which titanium is to be estimated, an inquiry was made as to their behavior when all are present at the same time. The following quantities were taken:

$$
\begin{array}{ll}
\text { Standard solution of } \mathrm{TiO}_{2} & \text { Io } \mathrm{cc} \text {. } \\
50 \mathrm{cc} \text {. solution of } \mathrm{Fe}_{2}\left(\mathrm{SO}_{4}\right)_{3} & =0.5000 \text { gram } \mathrm{Fe} . \\
0.9294 \text { gram alum } & =0.1000 \text { gram } \mathrm{Al}_{2} \mathrm{O}_{3} . \\
0.1000 \text { gram sodium phosphate } & =0.0200 \text { gram } \mathrm{P}_{2} \mathrm{O}_{5} .
\end{array}
$$

After diluting to $200 \mathrm{cc}$, ammonia and acetic acid were added as already described and the precipitate, after washing, was redissolved in hydrochloric acid, I: I. Some flocks of titanium phosphate, which obstinately resisted attack, were digested with concentrated hydrochloric acid, in which they finally dissolved. The solution was then neutralized and boiled for five minutes after saturating with sulphur dioxide. The color of the precipitated titanium dioxide varied from almost pure white to gray or brownish, and a considerable amount of impurity was present in each case, as may be seen from the following:
Weight of solution.
0.1052
0.1052
0.1055
0.1055
$0.0412+$
$0.0222+$
$0.0261+$
$0.0201+$

The precipitates were accordingly fused with sodium carbonate, dissolved by gently warming with strong sulphuric acid-the solution in this and similar instances was often incomplete, necessitating filtration and re-fusion-and after suitable dilution, pre-

\begin{tabular}{|c|c|c|c|c|c|}
\hline & & $\begin{array}{l}\text { Weight of } \\
\text { solution. } \\
\text { Grams. }\end{array}$ & $\begin{array}{c}\mathrm{TiO}_{2} \\
\text { found. (II) } \\
\text { Gram. }\end{array}$ & $\begin{array}{c}\mathrm{TiO}_{2} \text { by } \\
\text { standard. } \\
\text { Gram. }\end{array}$ & Errot. \\
\hline ( 15 & ..... & II. I 80 & O.IIO5 & 0.1052 & $0.0053+$ \\
\hline (16 & $\ldots$. & II.I74 & o. II 54 & 0.1052 & $0.0102+$ \\
\hline (17) & .... & II.2IO & O. I 203 & 0.1055 & $0.0148+$ \\
\hline (18) & .... & I 1,209 & O.II 27 & 0.1055 & $0.0072 t$ \\
\hline
\end{tabular}
cipitated with ammonia. Finally, a reprecipitation was made in the neutralized chloride solution, as described above, yielding the results stated below. 
Thus a double precipitation in a neutralized chloride solution fails to effect the complete separation of the titanium from the elements associated with it in this instance. It remained, then, to discover what amount of pure titanium dioxide was present in these precipitates and whether any one element was responsible for the magnitude of the error.

The precipitates were fused with sodium carbonate, leached with water, and re-fused with the same material. The mass was then dissolved in concentrated sulphuric acid with the aid of gentle heat and after pouring into water, in ( 15 ) and (16) hydrogen sulphide was passed in to saturation in order to discover whether appreciable amounts of platinum were present, an clement which is well known to contaminate titanium dioxide, if present during its precipitation; only traces were found and the question was considered as settled. After carefully adding ammonia till just alkaline, a quantity of dilute sulphuric acid equivalent to 2.5 grams of the pure acid was added, then 20 grams sodium acetate and sufficient acetic acid to make I I per cent. absolute acid in the solution. If ferric iron could be detected, sulphur dioxide was passed in at an appropriate stage. After boiling for three minutes and digesting on the water-bath for half an hour, the titanium dioxide was filtered off and washed with 7 per cent. acetic acid.

\begin{tabular}{|c|c|c|c|c|}
\hline & $\begin{array}{l}\text { Weight of } \\
\text { solution. } \\
\text { Grams. }\end{array}$ & $\begin{array}{l}\mathrm{TiO}_{8} \\
\text { found. (III) } \\
\text { Gram. }\end{array}$ & $\begin{array}{c}\mathrm{TiO}_{2} \\
\text { by } \\
\text { Gratadard. } \\
\text { Gram. } \\
\text { O.TO52 }\end{array}$ & $\begin{array}{c}\text { Error. } \\
\text { O.OIO4- }\end{array}$ \\
\hline$(15) \ldots \ldots$ & 11.180 & 0.0948 & 0.1052 & 0.0104 \\
\hline$(16) \ldots \ldots$ & II.I 74 & 0.0976 & o. 1052 & 0.0076 \\
\hline 7) $\ldots$ & I I. 2 IO & O. TOIO & 0.1055 & $0.0045-$ \\
\hline$(18) \ldots \ldots$ & II. 209 & 0.0968 & 0.1055 & 0.0087 \\
\hline
\end{tabular}

These precipitates still retained trifling quantities of iron.

With regard to the disturbing factor, some evidence may be given. After fusing 0.II05 gram of impure titanium dioxide obtained in the second precipitation in neutralized chloride solution in (15), with sodium carbonate and leaching with water, the phosphorus was determined in the extract and found to be equivalent to 0.0123 gram phosphorus pentoxide; the final precipitate from the acetic acid solution in the same instance weighed 0.0948 gram. $0.1105-0.0123=0.0982$ gram impure $\mathrm{TiO}_{2}-$ $\mathrm{P}_{2} \mathrm{O}_{3}$.

Any alumina would, of course, have been removed with the 
phosphorus, but, judging from the separation previously studied, there was now but a minute amount present and the difference $0.0982-0.0948=0.0034$ gram represents in all probability the iron eliminated, the latter clearly being indicated in the waste liquors by qualitative tests. Similar treatment of the titanium dioxide obtained in the second precipitation in the neutralized chloride solution in ( $\mathrm{I} 7$ ) and (I8) revealed the fact that phosphorus constitutes almost the entire impurity, with a small quantity of iron as its associate. In the filtrates from the neutralized chloride separations, titanium was found regularly and in amounts varying from traces to 3 or even 4 milligrams.

While, obviously, the attempted separation is rendered practically valueless by such serious losses in titanium, it must not be forgotten that the object was to subject the method to a severe test. The presence of the titanium phosphate no doubt made difficult the adjustment of the acidity of the solution, since it would be precipitated by the ammonia in neutralizing, and, dissolving very slowly or not at all, would induce the belief that but little free acid remained. Consequently the removal of the phosphorus and at the same time the remaining aluminum, after the first precipitation, by fusing with sodium carbonate and leaching with water should be undertaken, after which the problem resolves itself into the separation of iron and titanium, which has already been studied. Also, if a fusion with potassium bisulphate has been made at any stage, the platinum, which is invariably present, should be removed, preferably in hot sulphuric acid solution, before the final precipitation.

Brakes $^{1}$ has modified Baskerville's method by replacing the potassium bisulphate, used in the preliminary fusion, by sodium and potassium carbonates. The melt is dissolved in dilute hydrochloric acid, and, after filtering, the titanium is precipitated in the neutralized chloride solution as usual. Some results are given showing that closely agreeing figures may be obtained, but one cannot gather what degree of accuracy is reached.

ARNOLD'S METHOD.

Blair's statement that "when a solution of ferric chloride containing titanic and phosphoric acids is evaporated to dryness, a compound of titanic acid, phosphoric acid and ferric oxide is

1 Brakes: $J$. Soc. Chem. Ind., 18, rog7. 
formed, completely insoluble in dilute hyclrochloric acid," ${ }^{11}$ suggests a method of removing, with comparative ease and certainty, the large amount of iron and alumina which have usually to be separated from titanium in analytical work. Morgan" and Arnold ${ }^{3}$ have published methods founded upon this observation, and an inquiry was made as to their value. Waterhouset indeed states that the results may not be accurate, but presents no evidence in support of his assertion.

The descriptions may be abbreviated as follows: The finely ground ore, to which has been added I gram of ammonium phosphate, is treated with concentrated hydrochloric acid, the solution evaporated to dryness and baked for some time, then treated with dilute hydrochloric acid and the residue filtered off, the filtrate being discardecl. By fusing with sodium carbonate and leaching with water, the phosphorus and most of the silica and alumina are removed; the insoluble sodium titanate is brought into solution by treatment with potassium bisulphate, and the titanium dioxide precipitated from an acetic acid solution as described by Gooch. The crucial point is the insolubility of the phosphotitanate of iron in dilute hydrochloric acid, and neither of the authors specify the strength of the acid to be employed. In the descriptions which follow, the words "per cent." denote the parts by weight of anhydrous hydrochloric acid per 100 grams of solution.

The experiments were carried out in the following manner: A portion of the standard titanium dioxide solution was taken, and 0.5 gram iron as $\mathrm{Fe}_{2}\left(\mathrm{SO}_{4}\right)_{3}$ added; the hydroxides, precipitated by ammonia and a slight excess of acetic acid, were washed and dissolved in hydrochloric acid, and, after the addition of I gram of ammonium phosphate, the solution was evaporated to dryness and baked at the highest temperature of the hot plate for seven hours. To ascertain approximately the temperature to which the material was exposed, a thermometer was placed in an empty beaker on the same spot on the hot plate and left for some hours; the highest temperature reached was $180^{\circ} \mathrm{C}$. The cooled mass was then digested with 0.4 per cent. hydrochloric acid for some hours at a temperature of about $100^{\circ} \mathrm{C}$, , but no action of any

1 Blair's "Analysis of Jron and Steel," $4^{\text {th }}$ edition, p. 85.

2 Morgan: Chemical News, 75, I34.

3 Arnold: "Steel Works Analysis," p. 195.

4 Waterhouse: Chem. News, 85, 198. 
consequence ensued. With 2 per cent. hydrochloric acid, the hard mass softened and loosened from the bottom of the beaker after a short digestion; it was filtered off, washed, and the titanium dioxide in the filtrate estimated.

\begin{tabular}{|c|c|c|c|}
\hline & $\begin{array}{l}\text { Weight of } \\
\text { solution. } \\
\text { Grams. }\end{array}$ & $\begin{array}{c}\mathrm{TiO}_{2} \\
\text { taken. } \\
\text { Gram. }\end{array}$ & $\begin{array}{l}\mathrm{TiO}_{2} \text { in } \\
\text { filtrate. } \\
\text { Gram. }\end{array}$ \\
\hline . & I I.I $8 \mathrm{r}$ & 0.1052 & 0.0020 \\
\hline$\ldots .$. & I I. I 58 & o.I05I & 0.0025 \\
\hline
\end{tabular}

The residue containing the phosphotitanate still retained a large quantity of basic ferric salts, and, on following out the method of analysis as given, the final precipitation of the titanium dioxide had to be made in the presence of a considerable quantity of iron reduced to ferrous condition by sulphur dioxide. It is well known that unless the amount of iron be small, the separation under these circumstances is incomplete and in this experiment both of the precipitates of titanium dioxide were markedly contaminated with ferric oxide. To acquire further information, the experiment was repeated with slight modifications. The same quantities of titanium dioxide and ferric sulphate were taken; the baking lasted six hours; the mass was then digested with $50 \mathrm{cc}$. of 2 per cent. hydrochloric acid for two hours and finally boiled for half an hour. After filtering, estimations of the iron and titanium in the filtrate were made; the insoluble residue was returned to the beaker, $50 \mathrm{cc}$. of 4 per cent. hydrochloric acid added, and digestion carried on for fifteen hours at a temperature of $60^{\circ} \mathrm{C}$. The solution was again filtered and the iron and titanium estimated in the filtrate.

\begin{tabular}{|c|c|c|c|c|}
\hline & $\begin{array}{c}\mathrm{TiO}_{2} \\
\text { extracted. }\end{array}$ & $\begin{array}{l}\text { Total } \mathrm{TiO}_{2} \\
\text { extracted. }\end{array}$ & $\begin{array}{c}\mathrm{Fe} \\
\text { extracted. }\end{array}$ & $\begin{array}{l}\text { Total Fe } \\
\text { extracted. }\end{array}$ \\
\hline Two per cent. $\mathrm{HCl}(2 \mathrm{I}) \ldots \ldots$ & 0.0048 & $\ldots \ldots$ & 0.1700 & $\cdots \cdots$ \\
\hline$(22) \ldots \ldots$ & 0.0022 & $\ldots$. & 0.1140 & .... \\
\hline Four per cent. $\mathrm{HCl}(2 \mathrm{I}) \ldots \ldots$ & 0.0040 & 0.0088 & 0.1373 & 0.3073 \\
\hline$(22) \ldots \ldots$ & 0.0037 & 0.0059 & 0.1551 & $0.229 \mathrm{I}$ \\
\hline
\end{tabular}

Taken : $\mathrm{TiO}_{2}=0.1050 \mathrm{gram} . \mathrm{Fe}=0.5000 \mathrm{gram}$.

Taking mean values, 2 per cent. hydrochloric acid extracted 28 per cent. of the iron present and 3.5 per cent. of the titanium dioxide; 4 per cent. hydrochloric acid extracted 54.6 per cent. of the iron and 7 per cent. of the titanium dioxide.

A third trial was made with a titaniferous magnetite containing 44 per cent. of iron and I 3 per cent. of the titanitum dioxide. To I gram of the ore in impalpable powder were added. 
I gram ammonium phosphate and $20 \mathrm{cc}$. of concentrated hydrochloric acid, and digestion at a temperature of nearly $100^{\circ} \mathrm{C}$. was carried on for seven hours. The solution was evaporated to dryness, baked for five hours, digested with 2 per cent. hydrochloric acid for half a day and finally boiled for a short time. The same process was repeated with portions of the same acicl of greater strength.

\begin{tabular}{|c|c|c|c|}
\hline $\begin{array}{c}\mathrm{TiO}_{2} \\
\text { extracted. } \\
0.004 j\end{array}$ & $\begin{array}{l}\text { Total } \mathrm{TiO}_{2} \\
\text { extracted. }\end{array}$ & $\begin{array}{c}\text { Fe } \\
\text { extracted }\end{array}$ & $\begin{array}{l}\text { Total Fe } \\
\text { extracted. }\end{array}$ \\
\hline 0.0054 & $\ldots$ & 0.2175 & \\
\hline $0.003^{6}$ & 0.0070 & 0.1510 & 0.35 \\
\hline 0.0048 & 0.0102 & 0.1288 & 0.34 \\
\hline 0.0085 & 0.0164 & $0.048_{3}$ & 0.40 \\
\hline 0.0080 & 0.0182 & 0.0506 & 0.35 \\
\hline
\end{tabular}

Quantities present in sample: $\mathrm{TiO}_{2}=0.130$ gram $; \mathrm{Fe}=0.440$ gram.

Taking mean values we get:

$\mathrm{HO}_{2}$ extracted..$\ldots \ldots \ldots \ldots \ldots$

2 per cent. $\mathrm{HCl}$. Per cent.

Fe extracted............. 48

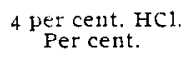

7

So
6 per cent. HC1. Per cent.

13

91

The serious inaccuracies to which the process is subject nullify its value as a method of separation, and only the possibility of its employment as a rapid, approximate method for technical work remains.

For such a purpose the following points should be noted. The baking should be thorough but not necessarily long; probably an hour at about $200^{\circ} \mathrm{C}$. is sufficient. Four per cent. hydrochloric acid should be used for the extraction of the iron, boiling until solvent action apparently ceases; if there remain a considerable quantity of reddish ferric salts, the strength of the hydrochloric acid may be raised to 6 per cent., which should on boiling almost complete the extraction. If 4 per cent. acid has been used, the probable loss in the titanium dioxide will be from 5 to ro per cent., with 6 per cent. hydrochloric acid, from Io to 15 per cent.

$$
\text { HILGER AND HAAS' METHOD. }
$$

While studying the separation of titanium and tin, Hilger and Haas $^{1}$ discovered that by igniting the mixed oxides in hydrogen and then boiling with dilute sulphuric or hydrochloric acid, the reduced tin could be dissolved without apparent loss in titanium. The method was also applied to the separation of titanium and

1 Hilger and Haas: Ber, $a$, chem. Gis., 23, 455 . 
iron, but no analytical results could be found in any of the literature to which the writer had access. For the analysis of ores and minerals the following process is recommended by the authors. The finely ground material is treated with sulphuric and hydrofluoric acids; after the removal of the silica, the latter acid is expelled by evaporation and the solution is transferred to a casserole, neutralized with potassium hydroxide, 2 grams sulphuric acid added, and the volume made up to $400 \mathrm{cc}$. The liquid is then boiled for six hours, the bulk being kept constant by adding water and the precipitated titanium dioxide filtered off; the acidity of the filtrate is again adjusted to 0.5 gram sulphuric acid per $100 \mathrm{cc}$, and a further boiling is carried on to recover any titanium which may still remain in solution. The total precipitate, which contains all the tin and a small quantity of iron, is then reduced in hydrogen for from fifteen to thirty minutes and boiled gently with 20 per cent. hydrochloric acid for half an hour. Tin and iron are dissolved, the titanium dioxide is filtered off, and, unless the amounts are small, the reduction and extraction are repeated.

Ledebur ${ }^{1}$ has described a modification of the process suitable for iron ores. The ore is reduced in hydrogen, boiled with dilute sulphuric acid I : 40, and the insoluble residue filtered off, treated with hydrofluoric acid, dried, fused with sodium carbonate, leached, re-fused with potassium bisulphate and the melt dissolved in water. The titanium dioxide is then precipitated by boiling for an hour at a bulk of $450 \mathrm{cc}$; no precautions for regulating the acidity of the solution are stated.

The important point is evidently the insolubility of the titanium dioxide, either as it occurs naturally or in the form of inetatitanic acid; some experiments covering this question were, therefore, made. For convenience, an iron ore was first tested according to Ledebur's directions, as given above. One gram of a titaniferous magnetic was reduced at a red heat in hydrogen for an hour and boiled in dilute sulphuric acid, I : 40 , for twenty minutes, the evolution of hydrogen ceasing after about ten minutes. Estimations were then made in the filtrate by color. In one experiment there was found 5 milligrams titanium dioxide, in another 5.2 milligrams. These would cause losses of 4 per cent. in the titanium dioxide found.

I Ledebur: Leitfaden $f$. Eisen. Lab., sth edition, p. $3^{8}$. 
In another case the same ore was reduced in hydrogen at a perceptibly higher temperature for two hours, and the filtrates tested after boiling in dilute sulphuric acid of the same strength. In one there remained 3.6 milligrams titanium lioxide, in the duplicate 4 milligrams; these correspond to losses of 3 per cent. in the titanium dioxide present.

To get an idea of the total losses which might occur in proceeding according to Hilger and Haas' directions, the following experiment was tried: To a weighed quantity of the standard titanium solution was added 0.5 gram iron as $\mathrm{FeSO}_{4}$, and the acility regulated to 0.5 gram sulphuric acid per $100 \mathrm{cc}$, as described. The solutions were boiled at a volume of $400 \mathrm{cc}$. for six hours with the addition of water as required, the precipitate was filtered off and the filtrates, aiter a renewed adjustment of the acidity, were subjected to a further boiling for two hours. The slight additional precipitate was added to that already collected, the whole dried and, after reduction in hydrogen for an hour and boiling for a short time with dilute sulphuric acid I $: 40$, the titanium dioxide was filtered off, ignited and weighed.

\begin{tabular}{|c|c|c|c|c|c|}
\hline $\begin{array}{l}\text { Weight of } \\
\text { solution. } \\
\text { Grams. }\end{array}$ & $\begin{array}{c}\text { TiO by } \\
\text { standard. } \\
\text { Gram. }\end{array}$ & $\begin{array}{l}\mathrm{TiO}_{\mathrm{g}} \\
\text { found. } \\
\text { Gram. }\end{array}$ & $\begin{array}{l}\mathrm{Fe}_{2} \mathrm{O}_{3} \\
\text { therein. } \\
\text { Gram. }\end{array}$ & $\begin{array}{l}\mathrm{TiO}_{2} \text { found. } \\
\text { less } \mathrm{Fe}_{2} \mathrm{O}_{3 .} \\
\text { Gram. }\end{array}$ & Error. \\
\hline . IIII42 & 0.1049 & 0.1008 & 0.0009 & 0.0999 & $0.0050-$ \\
\hline (26) . II.I30 & 0.1049 & 0.1088 & 0.0145 & 0.0943 & 0.0106 \\
\hline$(27) \ldots$ IIIIJ & 0.1047 & $0.0 \$ 88$ & 0.0004 & $0.088_{4}$ & $0.016_{3}$ \\
\hline (28) .. II.I22 & 0.1048 & 0.1017 & 0.0011 & c. 1006 & $0.0042-$ \\
\hline
\end{tabular}

The results in (25) and (28) agree with those obtained previously in the case of the ore, but (26) and (27) show a wide variation; no reason can be assigned for this behavior for (25) and (26) were carried out together and afterwards the other pair in like manner. The precipitation from the sulphuric acid solution was, in all cases, practically complete, as was shown by colorimetric estimations in the filtrates, while the same method revealed the fact that exceptionally large amounts were dissolved by the dilute sulphuric acid I : 40, in numbers (26) and (27). It would have been interesting to have had the record of some further experiments to enable one to juclge whether the heavy losses were extraordinary or not, but the best results already obtained were not very promising as regards accuracy, and other matters were more urgent. If we except numbers (26) and (27) -although there is no justification for this except the largeness 
of the error-the method will be seen to offer a slightly greater accuracy than Arnold's with a very convenient feature in the shape of the almost complete removal of the iron in the initial stage, without the heavy losses in titanium which accompany a treatment of phosphotitanate of iron with hydrochloric acid of a strength greater than 2 per cent. Even in Hilger and Haas, published work, among six results of separation of titanium from tin, three are subject to negative errors of $5.6,6.3$ and 7.5 per cent. in the amount of titanium dioxide found; such deficiencies are only negligible in dealing, as was the case in this instance, with small quantities of the element under discussion.

For the precipitation of titanium, Hilger and Haas make use of the directions given by Lévy, ${ }^{2}$ who has made an extensive study of some of the compounds of this element. In the course of the investigation, it was found necessary to test the analytical methods, and the discovery was made that titanium was completely precipitated on boiling a solution of its sulphate which contained 0.5 gram sulphuric acid per IOO cc.; in the presence of the alkalies, magnesium, zinc, copper, and even aluminum the separation was found to be complete. An instructive table is given by Lévy, which is reproduced below as an example of the manner in which the precipitation of titanium dioxide is influenced by the amount of free acid present. Portions of a solution of pure titanium sulphate were partially neutralized with potassium hydroxide and boiled for six hours at constant volume.

\begin{tabular}{|c|c|c|c|c|c|}
\hline So. & $\begin{array}{l}\text { Vol. of } \\
\text { liquor. } \\
\text { cc. }\end{array}$ & $\begin{array}{l}\text { Total } \\
\mathrm{H}_{2} \mathrm{SO}_{4} . \\
\text { Grams. }\end{array}$ & $\begin{array}{c}\text { Free } \\
\mathrm{H}_{2} \mathrm{SO}_{4} . \\
\text { Grams. }\end{array}$ & $\begin{array}{l}\mathrm{TiO}_{2} \\
\text { found. } \\
\text { Gram. }\end{array}$ & $\begin{array}{c}\mathrm{TiO}_{2} \\
\text { taken. } \\
\text { Gram. }\end{array}$ \\
\hline (1) $\ldots \ldots$ & 100 & $3.56 \mathrm{I}$ & 1.0 & 0.082 & 0.086 \\
\hline (2) $\ldots \ldots$ & 100 & 3.561 & 0.5 & 0.085 & 0.086 \\
\hline$\cdots \cdots$ & 100 & 3.561 & 0.0 & 0.100 & 0.086 \\
\hline$\ldots \ldots$ & 100 & $3 \cdot 5^{6 I}$ & 0.0 & 0.108 & 0.086 (excess of $\mathrm{KOH})$ \\
\hline ...... & I $5^{\circ}$ & 5.766 & 5.766 & 0.000 & 0.036 \\
\hline$\ldots \ldots$ & 150 & 5.766 & 0.083 & 0.036 & 0.036 \\
\hline$\ldots \ldots$ & I 50 & 5.766 & 0.000 & 0.047 & 0.036 \\
\hline
\end{tabular}

Iévy makes the statement that "In acetic acid, titanium dioxide is partially precipitated even in the cold, but never completely on boiling." No particulars of any experiments are given, but one wonders how he arrived at any such conclusion.

OTHER RECENTLY PROPOSED METHODS.

As has been intimated previously, the methods which have 1 Hilger and Haas : Loc, cit.

2 Lévy : Ann. chim. phys. [6], 25, 433. 
already been discussed were chosen because of the economy of time which they appeared to offer; of the other processes or modifications recently proposed which have come under the writer's notice, none appear to be free from objection, either on account of inaccuracy or of the amount of time required for their operation.

When in search of rapid methods one turns first to volumetric analysis, but unfortunately in that direction no accurate process for the estimation of titanium is available. Wiegand ${ }^{1}$ has studied the volumetric method proposed by Pisani ${ }^{2}$ and, with all the improvements which could be devised, found it still unsatisfactory. In the presence of titanium and iron the solution was reduced with zinc until the color no longer changed, then potassium permanganate was slowly added till a drop gave a red coloration with potassium thiocyanate. Errors of 3 to 4 per cent. are numerous among the results given; even with portions of a pure solution of titanium sulphate which were reduced and reoxidized, the errors in determination averaged 3.7 per cent. Wells and Mitchell, ${ }^{3}$ investigating the same method, proceeded upon a slightly different plan. Two equal quantities of a solution containing iron and titanium were taken, one was reduced with hydrogen sulphide, the other with zinc, the titanium being estimated by difference. Even with elaborate precautions, no better results were obtained. In ten determinations published, the lowest error was 2 per cent. and the highest 6 per cent.

Walkert has founded a method of separation from iron upon the observation that salts of titanium oxidized with hydrogen peroxide are not immediately precipitated by ammonia. An excess of the former reagent is added to the solution containing the two elements as sulphates and the whole is allowed to flow gently into ammoniacal hydrogen peroxide. Three separations were found to be necessary to separate 0.1 gram iron from the same amount of titanium dioxide; the results are excellent, but the number of operations appear to be a drawback.

In Rothe's $s^{5}$ method, which has found such extended use for the separation of nickel and iron, titanium, if present, remains

1 Wiegand: Ztschr, anal. Chem., 21, 510.

2 Pisani : Compt. Rend.. 59, 289.

3 wells and Mitchell: This Journal: 17, 879 .

* Walker: This Journal, 20, 513.

5 Rothe: Mith. König. Tech, Vełs. Anst, Berlin, 1892, Part III. 
in the acid solution and is therefore separated from iron; no analytical data are available, however, for guidance in forming an opinion.

Mathews ${ }^{1}$ has described as a means of separating iron from titanium, zirconium, and some of the rare earths, a modification of Rothe's method. The mixed, dried chlorides of the elements are heated with absolute ether and dry hydrochloric acid gas; the ferric chloride dissolves, leaving as a residue the chlorides of the other element or elements.

Although not at present very promising from the standpoint of speed, the three methods last described have interesting possibilities and deserve investigation; unfortunately, the time for a study of their efficiency has hitherto been lacking, but it is hoped that some experiments in this direction will shortly be carried ont.

As a result of the study which has been made, it has been found that Baskerville's method is superior in accuracy to either of the others, but the writer is of the opinion that the modification of Gooch's method, described by Blair, is the best which has yet been made public. An excellent and detailed description of this process is given by Pope $;{ }^{2}$ it does not take more time to carry out than does Baskerville's, and in the hands of the writer, has proved the more accurate.

Faculty of A pPLied ScIENCE,

UNIVERSITY OF TORONTO, July, IgO3.

[CONTRIBUTION FROM THE LABORATORy OF THE UNIVERSITY OF MiNNESOTA.]

\section{REDUCTION OF 2,5-DIMETHYLBENZALDAZINE AND THE PREPARATION OF SOME OF ITS SALTS.}

By Everhart Percy HaRdiNg aNd lillian CoHeN.

Received July 25, 1903 .

Preparation of the Hydrochloride of 2,5-Dimethyldibenzylamine. $^{3}$

$$
\begin{aligned}
& \left(\mathrm{CH}_{3}\right)_{2} \mathrm{C}_{6} \mathrm{H}_{3} \cdot \mathrm{CH}_{2} \\
& \left(\mathrm{CH}_{3}\right)_{2} \mathrm{C}_{6} \mathrm{H}_{3} \cdot \mathrm{CH}_{2}
\end{aligned}>\mathrm{NH} . \mathrm{HCl}-
$$

-From 2 to 5 grams of 2,5-dimethylbenzaldazine, prepared

1 Mathews: This Journal, 20, 846 .

2 Pope: Trans. Am. Inst. Min. Eng., 29, 372.

3 The free base-dimethyldibenzylamine has not yet been analyzed. 